\title{
Peregrinaciones a las fuentes de la medicina clásica
}

\author{
Ricardo Cruz-Coke $\mathbf{M}^{1}$. \\ A journey to the foundations \\ of classical medicine
}

The author narrates his trips, between 1951 and 2006, to the main historical sites of antique medicine, where physicians of pre-Columbian cultures of Mexico and Peru, Egypt, Greco Latin culture and Islamic civilizations, lived. The trip ends with a visit to medieval European medicine before Renaissance. A description of the main historical sites and the features of these medical and sanitary cultures is made. In antique civilizations, diseases were considered a punishment of pagan deities. Supernatural and magical influences were decisive in medical practice. The Greco Latin culture of Galen and Hippocrates freed manhood from these causes of diseases and gave a rational basis to the practice of medicine. The Islamic civilization allowed the transmission of Greco Latin culture to medieval Europe. This permitted the renaissance of European creativity and the foundation of modern scientific medicine in the sixteenth century. The author highlights the main virtues of classical Greco Latin medicine, that are the foundations of humanistic thoughts that will restrin the technological revolution of modern medicine (Rev Méd Chile 2007; 135: 1076-81).

(Key words: Hippocrates; History of Medicine; Renaissance)

Recibido el 7 de marzo, 2007. Aceptado el 7 de mayo, 2007.

${ }^{1}$ Academia Chilena de Medicina del Instituto de Chile (Miembro de Número)

$\mathrm{U}$ na peregrinación es un viaje hacia tierras extrañas para visitar lugares famosos en Arte, Ciencias o Religión. Definimos a la Medicina Clásica como aquella originada en la Antigüedad, que alcanzó su culminación en la cultura grecolatina y proyectó su legado hasta fundar la Medicina Moderna en el Renacimiento. Esta medicina clásica se extinguió en el Renacimiento científico europeo, que encabezaron los maestros que fundaron las ciencias básicas de la Medicina moderna. En este año de 2007 se cumplen cincuenta años de mi asistencia en Londres a mi primer congreso médico internacional, con ocasión del tercer centenario de la muerte de Harvey (1657).

Correspondencia a: Dr. Ricardo Cruz-Coke. Hospital Clínico Universidad de Chile. Santos Dumont 999, Santiago, Chile. E mail: rcruzcoke@redclinicauchile.cl
Desde entonces, como si fuera volando en la alfombra mágica de la Medicina, he peregrinado por más de 40 países asistiendo a más de 80 congresos, en que pude recorrer, acompañado por mi esposa, profesora de Historia, los lugares emblemáticos en que vivieron los maestros que echaron los cimientos de la Medicina Clásica. Este es un relato comentado de nuestras peregrinaciones ${ }^{1}$.

\section{PREHISTORIA}

Los historiadores de la medicina han recalcado que las enfermedades son anteriores a la aparición del hombre. Ellas surgieron en los mamíferos tras un largo proceso evolutivo. Así el origen de las enfermedades humanas se encuentra en los fósiles de los mamíferos prehistónicos extintos. Homo es un genero de la familia Hominidae de Primates que incluye a la 
especie humana, que en 1735 Linneo bautizó como «Homo sapiens». Las especies Homo extintas hace millones de años son el Australopitecus, el Homo habilis y el Homo erectus. Los hombres de Neandertal y de Cromagnon se extinguieron hace sólo cientos de miles de años. Por tanto la medicina se originó al finalizar el proceso de hominización con el surgimiento del Homo sapiens en el contexto de la evolución de la paleopatología de los primates ${ }^{2-6}$.

Durante mis estudios de postgrado en Europa visité los Museos de Ciencias Naturales y de Antropología de Londres y de París, y más tarde conocí las cavernas de los hombres prehistóricos en Lascaux, Gibraltar y Pekin ${ }^{7,8}$.

Al llegar el período Neolítico, hace unos 15 a 20 mil años, la nueva especie Homo sapiens sapiens logró evolucionar culturalmente y crear una medicina primitiva, cuya práctica aún persiste en regiones rurales aisladas de África y América. Pero en otras regiones ecológicamente privilegiadas del mundo, lograron surgir importantes culturas arcaicas que formaron una medicina autóctona, más evolucionada ${ }^{3,4}$.

\section{LAS CULTURAS MÉDICAS PRECOLOMBINAS}

Los pueblos originarios de América ingresaron al continente por el estrecho de Behring hace unos 28 mil años. Avanzando hacia el sur, el poblamiento perdió su carácter nómada hasta instalarse en tierras agrícolas donde iniciaron el periodo neolítico, 5.000 años a.C. Las grandes culturas arcaicas surgieron 1.200 años a.C. en Mesoamérica y los Andes. Cuando llegaron los españoles en el siglo XVI encontraron civilizaciones con un desarrollo muy primitivo, puesto que no habían alcanzado la Edad del Bronce como en el Viejo Mundo. No conocían el arado, la rueda, el molino, la destilación del alcohol, el vidrio, la fundición de hierro ni el arco arquitectónico. Su medicina estaba basada en el concepto de enfermedades mágicas y misteriosas, donde las influencias sobrenaturales y religiosas eran decisivas para la práctica médica. Pero cada una de las civilizaciones incaica, azteca y maya tenía caracteres singulares $3,4,9$.

Mis investigaciones sobre las culturas Andinas se iniciaron con mi estadía en Perú, en 1959 y 1960, donde estudié la epidemiología genética de la hipertensión arterial en pueblos quechuas y aimaraes. Los incas dirigían un estado socialista monárquico basado en la consanguinidad incestuosa de primer grado. El inca Huáscar (1525-1532) habría tenido 44\% de sus genes idénticos por descendencia del fundador del imperio Manco Capac (1210), acumulados desde diez generaciones (un sistema similar a los faraones). Su teogonía médica decía que el Dios Viracocha envió a su hijo a enseñar herbolaria al pueblo para evitar y curar las enfermedades. En efecto, la salud del pueblo se beneficiaba por maravillosas plantas medicinales como la coca, lobelia, quina, que eran usadas en forma empírica. Además disponían de los mejores alimentos autóctonos: maíz, patatas, tomates, nueces. La profesión médica era hereditaria y estaba subdividida en múltiples especialidades. El médico tenía un conocimiento limitado de la anatomía, pero hacía cirugía menor, traumatología y hasta trepanaciones craneales. Sus enfermedades endémicas eran el bocio, la veruga y la sífilis. Los niños malformados eran eliminados y se hacían sacrificios humanos de jóvenes en ceremonias religiosas. El pueblo quechua interpretaba a las enfermedades como resultado de sus pecados y de fuerzas mágicas. El concepto de enfermedad no existía, pero sí se identificaban algunos signos y síntomas: dolor, vómito, diarrea, tos, hemorragia y escalofíos. La momificación de los cadáveres era práctica fácil por la sequedad del clima. Las momias de los incas tenían máscaras de oro al igual que la de Tutankamon ${ }^{4,9-12}$.

Visitamos las culturas azteca y maya en la década de 1970. Los templos de la plaza mayor de la ciudad de México y las pirámides de Teotihuacán (120 dC) me impresionaron más que las ciudades megalíticas del imperio Inca. Los médicos aztecas originaban su profesión de los médicos nahuatl que recibían la enseñanza tutorial del Dios Tlaloc. Basada en una superstición religiosa, la medicina nahuatl relacionaba los dioses con las enfermedades y por tanto hacían sacrificios humanos para satisfacerlos. Esta práctica siniestra repugnó a los españoles, que reaccionaron destruyendo no sólo sus ídolos y los templos ensangrentados, sino también sus valiosos códices. Pero la práctica empírica de los aztecas era buena en cirugía menor, traumatología y herbolaria, pues tenían hierbas para calmar el dolor y mejorar los síntomas y signos de las enfermedades de ellos y de sus conquistadores ${ }^{9,12}$.

El Imperio nuevo de la cultura maya (9871541) se destaca en Chichen Itza con la pirámide de Kukulkán, el Castillo que es la plasmación del 
calendario maya y el edificio del caracol que es un Observatorio astronómico. Pero también está el cenote, un pozo profundo donde se arrojaban las doncellas en los sacrificios humanos a los dioses. En el templo de los guerreros el Dios Choc Mool mira de frente para recibir las ofrendas. Los mayas tenían la medicina más evolucionada, dioses para cada enfermedad y médicos especializados, que pertenecían a la clase sacerdotal de Chilam balan, haciendo su práctica en los templos. Calculaban el tiempo, hacían augurios, predecían las epidemias y controlaban sus enfermedades autóctonas: pinto, leishmaniasis, frambesia y sífilis, con hierbas medicinales. El sacrificio humano era la base del culto religioso en sus templos. Los médicos integraban un cuerpo sacerdotal que incluía astrónomos, escribientes, adivinadores y sacrificadores. Los fallecidos eran enterrados en su propia casa, pero los nobles eran incinerados y su cráneo se conservaba en un altar. Los aztecas creían en la transmigración de las almas en un paraíso $4,9,12$.

$\mathrm{Si}$ bien las culturas arcaicas mesoamericanas alcanzaron gran desarrollo en la arquitectura, la astronomía y la escritura, el predominio religioso y mágico que ejercieron los gobernantes sobre la población, impidieron la libertad de los médicos y sanadores para crear una medicina autónoma y racional, etapa que habían logrado alcanzar hacía más de mil años, algunos pueblos del mar Mediterráneo, bajo el milagro griego.

\section{LA MEDICINA DE LOS EGIPCIOS}

Al recomer el British Museum y el Louvre, en 1951, me impresionaron las ricas colecciones de tesoros de la cultura egipcia, saqueados por el imperialismo europeo del siglo XIX. En 1960 visité los museos de El Cairo y la mítica tumba de Tutankamon en el valle de los Reyes. De la lectura de las descripciones clásicas de los egiptólogos, conocía la sabidunáa de los egipcios como un pueblo altamente dotado con gran capacidad para las realizaciones prácticas, pero a la vez incapaces de desarmollar un pensamiento abstracto y componer una filosofía verdadera, debido al inmenso poder de una cultura faraónica religiosa excluyente y absoluta. La medicina clásica de los faraones era fundamentalmente religiosa, porque la enfermedad era concebida como un castigo de los dioses que eran representados por seres humanos con cabeza de bestias: Horus, el halcón; Anubis, el chacal. Estos dioses sanadores eran invocados para obtener salud. La enfermedad era un desequilibrio de las relaciones de seres sobrenaturales y la salud sólo podía restablecerse mediante métodos mágicos para expulsar del cuerpo a los malos espínitus. El primer gran médico egipcio Imhotep (2700-2650 a.C.) era arquitecto y construyó la pirámide escalonada de Sakkara, por orden del faraón Djoser, instalando una medicina del trabajo para proteger la salud de los trabajadores de los monumentos de piedra. En el año 1.000 los sacerdotes lo elevaron a rango de Dios y lo equipararon a Asclepios, el dios sanador de los griegos ${ }^{4,13,14}$.

En el Museo de Antigüedades de El Cairo se exhiben las momias de los faraones, los papiros egipcios y los tesoros de la tumba de Tutankamon (1347-1339 a.C.) con la maravillosa máscara de oro que cubre su rostro. Los detalles del proceso de momificación están bien expuestos. La costumbre de embalsamar a los muertos ejerció poderosa influencia en el desarrollo de la medicina, ya que se hacía una anatomía práctica y se conocían todos los órganos del cuerpo humano. El análisis de la momia de Tutankamon, consolidó el conocimiento de la historia de la decimoctava dinastía de consanguinidad incestuosa, como era la incaica. Pero los papiros egipcios son el legado más preciado, ya que son los documentos de la más antigua literatura médica del mundo. El papiro de Meshaik, del año 900 d.C., está escrito en copto y contiene recetas, segmentos de papiros faraónicos hieráticos, que reproducen partes de los famosos papiros antiguos de Ebers, de Hearts y de Smith. Estos documentos demuestran continuidad de la medicina mágica con la medicina empínca. Describen las enfermedades digestivas, cardíacas, pulmonares, y de los órganos de los sentidos. En cirugía se describe la curación de las heridas. Y en terapéutica se enumeran las recetas mágicas junto con el uso de drogas de popularidad universal como el aceite de ricino, la mandrágora, el comino, el llantén y el cilantro. Así Egipto legó conocimientos populares y mágicos a la medicina universal. También fue la primera cultura médica que legó los primeros libros médicos, y las observaciones de anatomía, los primeros experimentos en cirugía, la preparación de recetas de farmacia y un vocabulario médico $4,5,13,14$.

$\mathrm{Al}$ igual que las culturas arcaicas precolombinas, la medicina de los faraones, a pesar de sus 
excelentes progresos empíricos, no logró liberarse de la rígida teocracia de los dioses del Nilo, y sólo pudo transmitir su medicina utilitarista a los otros pueblos del mar mediterráneo.

\section{LA CULTURA GRECO LATINA}

Visité los museos de Londres, París y Roma y quedé deslumbrado por los tesoros de la cultura griega. Al recorrer Grecia, la mitología griega encantaba los lugares donde aparecían las estatuas de los dioses del Juramento Hipocrático y las estatuas del dios de la medicina, Asclepios (Esculapio) y su hija Higeia, la diosa de la Salud, cuyo busto está en la entrada del palacio de la OMS en Ginebra. El culto de estos dioses comenzó en el siglo VI a.C. y se extendió por toda Grecia. Sus templos y acrópolis sagradas, están en Epidauro, Pérgamo, Kos y Rodas. La estatua de Esculapio presenta una culebra que simbolizaba sus poderes sanadores mediante los sueños de sus pacientes. Así el dominio de los dioses de la Salud era semejante al poder de los dioses de América y de Egipto. Pero este respeto y reconocimiento de los dioses y de las fuerzas sobrenaturales de las culturas antiguas, no impedían abrir el camino para crear una medicina independiente de esos dioses.

Durante los siglos V y IV algunos hombres de genio del milagro griego, con conocimiento de los fenómenos naturales y profundo razonamiento, ofrecieron una visión congruente y ordenada del universo. Se formó así una concepción científica de la medicina universal, liberada de las influencias de la religión y de la filosofía, y establecida en forma progresiva como un conocimiento técnico. Médicos de la escuela de Hipócrates, al observar al hombre y su medio ambiente, razonando sobre la causa y el efecto, y apreciando los fenómenos similares y opuestos, dieron a la práctica médica una base racional. La ciencia médica griega, en estrecha compañía con la filosofía, traspasó los linderos de una simple profesión para convertirse en una fuerza cultural de primer orden. La época de oro de Grecia proyectó el espíritu clásico de su Filosofía y su Medicina en forma conjunta hacia el porvenir. De este modo quedaba superado el empirismo utilitario de la medicina de los egipcios, que no contenía ninguna filosofía médica racional ${ }^{4,15-17}$.

Con Hipócrates de Kos (460-377 a.C.) nació el arte médico europeo, ayudado por los filósofos
Platón y Aristóteles que influyeron decisivamente en el desarrollo de la medicina helenística, liderada por la sabidunía y la práctica experimental de Herofilo (335 a.C.) y de Erasistrato (304-250 a.C.) los cuales sistematizaron el saber médico anatómico hasta la aparición de Galeno (130-210 d.C.) en pleno Impeno Romano. Con la obra de este gran médico griego, la medicina clásica iba a alcanzar su clímax en la Antigüedad. Nacido en Pérgamo, formado por los mejores médicos de su tiempo, ejerció la medicina en Roma y fue médico de los emperadores Marco Aurelio, Cómodo y Séptimo Severo. Escribió más de 300 trabajos y libros, recopilados en 20 volúmenes en griego y latín por C.G. Kuhn; Opera Omnia, Leipzig (1821-1833). Galeno, heredero de Hipócrates, estableció el conocimiento sistemático de la anatomía humana aplicada al diagnóstico y tratamiento de las enfermedades. Usó la lógica aristotélica como fuente del conocimiento científico. La anatomía galénica que iba a predominar durante 14 siglos era una concepción teleológica en función de la actividad del ser humano. Su sistema fisiológico presentaba una visión completa de las funciones vegetativas, animales y racionales. Negaba la existencia de causas sobrenaturales y de enfermedades de origen divino. Sin embargo, Galeno aceptaba la existencia del alma y la idea de un Dios que no tenía poder para alterar los fenómenos de la naturaleza. $\mathrm{Al}$ compartir la filosofía del monoteísmo, las traducciones de sus libros médicos y filosóficos fueron reconocidos y difundidos en la Edad Media por judíos, mahometanos y cristianos ${ }^{16-19}$.

Recordamos a Galeno al visitar las ciudades en que vivió. La antigua Pérgamo tiene el templo de Asklepios donde trabajó Galeno. Cerca de Trieste está Aquilea que fue el cuartel general de invierno de los emperadores romanos en su lucha contra los bárbaros en el frente del Danubio. Ahí llegaba Galeno apresuradamente desde Roma para atender las enfermedades de Marco Aurelio y de Cómodo, En Roma el palacio imperial -la Domus Aurea- recién restaurado recuerda su famosa visita médica a Marco Aurelio, para atender el dolor del vientre del César y sanarlo. Con la muerte de Galeno el pensamiento griego perdió su capacidad creadora y se detuvo el desarrollo de la Medicina Clásica. Algunos médicos latinos recompusieron su obra escrita en idioma griego, que sería propagada al mundo bizantino y a las lenguas orientales. Pero su recuerdo imperecede- 
ro sería inmortalizado siglos más tarde con el advenimiento de la civilización islámica.

\section{LA MEDICINA DE LA CIVILIZACIÓN ISLÁMICA}

En los primeros siglos de la expansión del Islam (VII-IX d.C.), el idioma árabe fue la lengua común que permitió la transmisión de la filosofía, ciencia y medicina de la cultura greco latina a la Europa occidental en la Edad Media. Los médicos nestorianos tradujeron del griego al árabe en el siglo IX, las obras de Aristóteles, Platón, Hipócrates y Galeno. Así la medicina tribal beduina entró en contacto con la medicina científica griega y se formaron médicos filósofos con amplia cultura matemática, de astronomía, lenguaje y música. La ética médica islámica tenía profundas raíces religiosas en el Alcorán. El progreso y expansión de la civilización islámica desde Persia hasta España, creó una educación médica en las madrasas de las mezquitas, desarrolló la química y la farmacia, la publicación de libros médicos y la fundación de hospitales en Bagdad, El Cairo, Damasco, Túnez, Fez y Marrakech ${ }^{4,20,21}$.

Después de asistir a diversos congresos en ciudades islámicas, he visitado además Toledo y Cóndoba, donde quedan los restos de la España musulmana. Toledo fue durante la Edad Media la plaza mayor de la cultura hispana. Hace mil años era una ciudad de tres culturas visitada por los intelectuales europeos que venían a buscar las traducciones de los libros de los idiomas árabes, latín, griego y persa. Así, en 1135, el arzobispo de Toledo fundó una escuela de traductores de los manuscritos árabes al latín, en que participaban clérigos católicos, judíos y mozárabes. Con la llegada de Gerardo de Cremona (1114-1187) se comenzaron a traducir los textos árabes de Hipócrates, Galeno y los andaluces Abulcasis, Rhazes y el Canon de Avicena. De este modo, todos estos manuscritos fueron pasados a la imprenta durante el Renacimiento ${ }^{20-22}$.

Córdoba, anclada sobre el Guadalquivir, con su puente romano y su inmensa mezquita, hoy catedral, mantiene sus barrios mozárabes, judíos, y su Medina. Ahí nacieron Abulcasis (936-1013), Averroes (1126-1198) y Maimónides (1135-1204) cuyos libros clásicos fueron traducidos del árabe al latín. Abulcasis fue el máximo cirujano islámico y su enciclopedia Al-Tasrif contiene un moderno tratado de cirugía que se adelantó a los cirujanos europeos del Renacimiento. Averroes, gran filósofo, editó el Colliget, un libro general de Medicina. Cayó en desgracia por sus ideas heréticas sobre el alma y se refugió en Marrakech. Maimónides, el principal filósofo y médico judío de la Edad Media, fue autor de textos médicos de aforismos basados en Hipócrates y Galeno. También debió huir a Fez en 1158. A Maimónides le debemos la famosa plegaria del Médico, que comienza «lena mi ánimo de amor por el Arte y para todas las criaturas», que se conserva en todos los textos de Ética Médica del mundo $20-23$.

Fez, estratégicamente situada en Marruecos, fue una ciudad hispano-morisca hace mil años y refugio para los perseguidos de los califas de Córdoba, Marrakech y de Kairuan. Sus visires protegieron a Maimónides, Averroes y Abulcasis de las persecuciones andaluzas. Pero, en 1165, Maimónides decidió emigrar a Egipto para refugiarse en la judería de El Cairo. Fue médico de Saladino en Egipto y Palestina y fue enterrado en la ribera del lago Tiberiades, en $1204^{20,23}$.

Un historiador alemán sentenció; «Mirando el pasado podemos afirmar que la Medicina y la Ciencia islámicas fueron reflejo del sol helénico en sus días de ocaso, que brillaron como la luz lunar iluminando la noche medieval europea y que algunas estrellas de primera magnitud tuvieron destellos de luz propia. Estas se apagaron con la aurora del Renacimiento. Como ayudaron al nacimiento de Europa es justo reconocer que aún viven entre nosotros 20 .

\section{LA ALBORADA DE LA MEDICINA RENACENTISTA}

Durante los últimos siglos de la Edad Media, XIV y $\mathrm{XV}$, Europa occidental vivió grandes desastres, epidemias, guerras interminables, anarquía social y política, y decadencia de la población rural que emigró a las ciudades. Sin embargo, dentro de este contexto adverso, la medicina medieval europea comenzó a recibir influencias positivas con la invención de la imprenta, el desarrollo de las universidades y la llegada de los manuscritos griegos de la civilización islámica, a través de los traductores de Toledo y Salemo. La medicina medieval comenzó a tener un carácter laico y científico a partir de la creación de la escuela médica de Salemo en el siglo X. Por su estratégica situación al sur de Nápoles y abierto al 
comercio de las Magna Grecia del sur de Italia, Salerno se transformó en una «ciudad hipocrática», donde se agnuparon médicos árabes, griegos y latinos para recibir la transmisión del legado de Hipócrates y Galeno. Salemo se fortaleció con la llegada de Constantino el Africano en 1065, un comerciante de drogas que se asoció con los monjes benedictinos de Monte Casino y tradujo innumerables obras de Hipócrates y Galeno al latín. Lamentablemente, Salerno fue saqueada en 1194 por el emperador germánico Ennique VI. Los médicos graduados en Salemo se dispersaron por Europa y ayudaron a fundar durante el siglo XIII las primeras escuelas de medicina europeas en Montpellier, Padua, Nápoles, Bologna y París, en cuyas universidades se forjó la alborada del Renacimiento ${ }^{4,19,20}$.

Después de la caída de Bizancio en poder de los turcos, en 1453, y con la invención de la imprenta, se inició una revolución de comunicación cultural en la

\section{REFERENCIAS}

1. Aluende J. La alfombra mágica de la ciencia. Huella y Presencia 1992; 1: 23-26.

2. Castiglonion A. Histoire de la Medecine. Edit. Payot. Paris, 1931.

3. Lain Entralgo P. Historia de la Medicina, Salvat Editores, Barcelona, 1978.

4. GuerRA F. Historia de la Medicina, Vol 1. Edit. Norma. Madrid, 1982.

5. Enciclopedia Salvat. Vol. 10. Salvat Editores, Madrid. 2004.

6. Británica Enciclopedia Universal Ilustrada. Vol 10. Santiago, 2006.

7. Cruz-Coke R. El Hombre y su planeta. Cap. 5. Edit. Andres Bello, Santiago, 1962.

8. Teilhard de Chardin P. Le phenomene humain. Paris, 1955.

9. Salvat Editores. Historia Universal. Tomo 14. Civilizaciones precolombinas, Lima, 2005.

10. CRUz-CokE R. Estudio ecológico de la hipertensión arterial. Rev Méd Chile 1960; 88: 263-70.

11. Cruz-Coke R. Consanguinidad parental. Rev Méd Chile 1965; 93: 583-7.

12. VIesCa C. Medicina prehispánica de México. Panorama editorial. México D.F. 1992.

13. Carter H. La tumba de Tutankamon. Espasa Calpe. Barcelona. 1993. medicina, que transformó la educación médica, la regulación de las profesiones de la salud y la renovación de las técnicas médicas y quinúrgicas. De este modo, se abrieron las puertas para la entrada en escena de los grandes médicos creadores de la medicina modema científica, tales como Vesalio, Serveto, Paracelso y Paré. Ellos impulsaron los descubrimientos médicos que completaron, la descripción de la Anatomía sistematizada del cuerpo humano y la Fisiología que descubrió el funcionamiento de los Aparatos Circulatorio, Respiratorio y Urogenital. Sobre estas ciencias básicas se crearon las disciplinas y especialidades de la medicina actual que se formaron en los siglos del Barroco y de la Ilustración. Sin embargo, senía el legado de la antigüedad clásica, con su medicina integrada con la Filosofía, la Religión y las Artes, con sus valores y sus virtudes, la que mantendnía vivo el fuego sagrado del Humanismo en los tiempos contemporáneos ${ }^{24-27}$.

14. Dawson W. El Legado de Egipto. Medicina. U. Oxford. Ed. Pegaso. Madrid, 1950: 277-302.

15. Jaeger W. Paideia. Los ideales de la cultura griega. Fdo Cultura Económica. México, 1944.

16. Singer C. El Legado de Grecia. Medicina. U. Oxford. Ed. Pegaso, Madrid, 1956: 273-340.

17. CRUz-Coke R. La Filosofía hipocrática. Rev Méd Chile 1999; 127: 611-14.

18. Galeno C. Tratados filosóficos y autobiográficos. Ed. Gredos. Madrid, 2002.

19. GRMEK M. Histoire de la pensée médicale en Occident. Vol I. Seuil, Paris, 1995: 95-122.

20. MeYerhoff M. El legado de Islam. Ciencia y Medicina. U. Oxford. Ed. Pegaso, Madrid, 1944: 405-63.

21. AMAR S. Trois grands medecins andalous, ISHM. Carthage, Tunis, 1998.

22. García de Cortázar F. Atlas de Historia de España. Ed. Planeta. Barcelona, 2005.

23. Goic A. Grandes médicos humanistas. Edit Universitaria. Santiago, 2004.

24. Dupont M. Dictionnaire historique des Médecins. Larousse. Paris, 1999.

25. Cruz-Coke R. Historia de la Medicina Chilena. Cap. 8 Edit. Andres Bello, Santiago, 1995.

26. Cruz-Coke R. Vesalio. Rev Estud Med U Chile. Año II (1), Santiago, 1945.

27. Cruz-Coke R. Genética Social. Editorial Universitaria, Santiago, 1999. 